\title{
Comparative evaluation of the safety and efficacy of recombinant FVIII in severe hemophilia A patients
}

\author{
Hassan Abolghasemi, MD', Yunes Panahi, PhD², Minoo. Ahmadinejad, MD², \\ Gholamreza Toogeh, MD4, Mehran Karimi, MD ${ }^{5}$, Aziz Eghbali, MD', \\ Nargess Bigom Mirbehbahani, MD ${ }^{7}$ Bighan Keikhaei Dehdezi, MD $^{8}$, \\ Zahra Badiee, MD9, Hamid Hoorfar, MD ${ }^{10}$, Peyman Eshghi, MD1, \\ Nader Maghsoudi, PhD ${ }^{11}$, Amirhossein Sahebkar, PhD ${ }^{12,13,14}$, \\ Mohammad Gholami- Fesharaki, PhD ${ }^{15}$
}

\footnotetext{
${ }^{1}$ Pediatric Congenital Hematologic Disorders Research Center, Shahid Beheshti University of Medical Sciences, Tehran, Iran.

${ }^{2}$ Pharmacotherapy Department, Faculty of Pharmacy, Baqiyatallah University of Medical Sciences, Tehran, Iran.

${ }^{3}$ High Institute of Research, Iranian Blood Transfusion Organization, Tehran, Iran.

${ }^{5}$ Hematology Research Centre, Shiraz University of Medical Sciences, Shiraz, Iran.

${ }^{6}$ Department of Pediatric Hematology-Oncology, Mofid Children's Hospital, Shahid Beheshti University of Medical Sciences, Tehran, Iran. ${ }^{7}$ Golestan University of Medical Sciences, Gorgan, Iran.

${ }^{8}$ Department of Thalassemia \& Hemoglobinopathy Research Center, Ahvaz Jundishapur University of Medical Science, Ahvaz, Iran.

${ }^{9}$ Doctor Sheikh Hospital, Mashhad University of Medical Sciences, Mashhad, Iran.

${ }^{10}$ Isfahan University of Medical Sciences, Isfahan, Iran.

${ }^{11}$ Neuroscience Research Center (NRC), Shahid Beheshti University of Medical Sciences, Tehran, Iran.

${ }^{12}$ Biotechnology Research Center, Pharmaceutical Technology Institute, Mashhad University of Medical Sciences, Mashhad, Iran.

${ }^{13}$ Neurogenic Inflammation Research Center, Mashhad University of Medical Sciences, Mashhad, Iran.

${ }^{14}$ School of Pharmacy, Mashhad University of Medical Sciences, Mashhad, Iran.

${ }^{15}$ Department of Biostatistics, Faculty of Medical Sciences, Tarbiat Modares University, Tehran, Iran.
}

\section{Key Words}

Hemophilia A, Recombinant Factor VIII, Safacto, Xyntha.

\section{Abstract \\ Objective: This study compared the safety and efficacy of Safacto ${ }^{\circ}$ versus xyntha ${ }^{\circ}$ in patients with severe hemo- philia A.}

Methods: Thirty-three male patients with severe hemophilia A were randomly divided into two groups. Seventeen patients received Safacto ${ }^{\circ}$ and 16 patients received Xyntha ${ }^{\circ}$ for four consecutive times. The dosage of FVIII was 40-50 IU $/ \mathrm{kg}$ for each injection. Plasma level of FVIII activity was evaluated before every injection,
15 minutes after the injection and one month after the start of the trial. The rate of factor VIII activity, pain and joint motion were also assessed before and after the treatment.

Results: Plasma level of FVIII clotting activity in Safacto ${ }^{\circ}$ and Xyntha ${ }^{\circ}$ were $1.96 \pm 0.5 \mathrm{IU} / \mathrm{dl}$ and $1.63 \pm 0.5 \mathrm{IU} / \mathrm{dl}$ and increased to $88.84 \pm 25.2 \mathrm{IU} / \mathrm{dl}$ and $100.09 \pm 17.8 \mathrm{IU} /$ $\mathrm{dl}$, respectively $(\mathrm{P}<0.001)$. Pain score and range of motion improvement were $9.3 \pm 0.9$ and $8.7 \pm 0.1$ in Safacto ${ }^{\circ}$ $(\mathrm{P}=0.17)$; and 9.4 \pm 0.8 and $8.8 \pm 0.3$ in Xyntha ${ }^{\circ}(\mathrm{P}=0.35)$, respectively. No allergic or other unfavorable reactions was observed with either of the preparations.

Conclusion: This study showed that Safacto ${ }^{\circ}$ has a favorable efficacy and safety profile.

Received: Sep 12, 2017 Reviewed: Mar 20, 2018 Accepted: May 17, 2018

(c) This is an Open-Access article distributed under the terms of the Creative Common Attribution Non-Commercial License (http://creativecommons.org/licenses/by-nc/4.0/) which permits unrestricted noncommercial use, distribution, and reproduction in any medium, provided the original work is properly cited.

(@) This paper meets the requirements of KS X ISO 9706, ISO 9706-1994 and ANSI/NISO Z39.48-1992 (Permanence of Paper).
"Corresponding Author

Yunes Panahi Professor of critical care pharmacotherapy

Pharmacotherapy Department, Faculty of Pharmacy, Baqiyatallah University of Medical Sciences, Tehran, Iran.Yunespanahi@yahoo.com

Tel: +989123270993 Fax :+982188211524

(c) 2018 Korean Pharmacopuncture Institute

http://www.journal.ac 


\section{Introduction}

Factor VIII (FVIII) deficiency or hemophilia A is caused by the absence of FVIII which is a clotting protein [1]. Hemophilia A is an X-linked recessive trait genetic disorder with a prevalence of 1 in 5000 live births in males that leads to spontaneous bleeding in muscles, joints and digestive tract .

FVIII or antihemophilic factor is a large plasma glycoprotein that is encoded by the F8 gene and mainly synthesized by multiple tissues such as liver, kidney and lymphatic tissues. Hemophilia is classified as mild, moderate and severe. In the severe form, the serum level of FVIII is below $0.01 \mathrm{IU} / \mathrm{ml}$. In moderate and mild forms, the serum level of FVIII is $0.01-0.05 \mathrm{IU} / \mathrm{ml}$ and $0.05-0.40 \mathrm{IU} / \mathrm{ml}$, respectively [2]. In patients with severe hemophilia, frequent spontaneous bleeding occurs that may reach as high as 30 times a year. The patients may experience intracranial or retroperitoneal bleeding. In patients with moderate form, hemarthroses are the major findings. Bleeding in soft tissue after minor trauma also occurs. In the mild form, patients experience only bleeding disturbances after major injuries, trauma or surgery.

Treatment of hemophilia is based on increased activity of defective factor in the blood. Different products such as human plasma-derived lyophilized FVIII, recombinant FVIII, desmopressin, and anti-fibrinolytic and local hemostatic drugs have been used for the treatment of hemophilia.

In Iran, about 7000 patients are living with hemophilia [2]. A significant number of these patients need plasma-derived or recombinant coagulation factors [3]. The cost of plasma- derived coagulation factors is a substantial burden on Iran's health care sector [2]. Based on personal communications with Iran Blood Transfusion Organization, mean per capita for FVIII in patients with hemophilia A is $3.5 \mathrm{IU}$ in Iran, which is greater than the global mean. To decrease the treatment costs and supply standard medical care to the patients, Iranian health organizations seek alternative options like recombinant coagulation factors. The Iranian government highly subsidizes imported recombinant coagulation factors but the availability of these products depends on existing financial resources. Concerning these issues, local production of the recombinant coagulation factors is the most practical option [2]. Safacto ${ }^{\circ}$ is a B-domain-deleted and albumin-free FVIII product. Cell line culture of Safacto ${ }^{\circ}$ isChinesehamster'sovary $(\mathrm{CHO})$ purifiedwithasyntheticligand[4].Safacto ${ }^{\circ}$, as a local recombinant FVIII product, has been compared with a plasma-derived FVIII in a crossover study in which acceptable results and good outcomes in the patients were observed [5].

The purpose of this study was to compare the safety and efficacy of the Iranian recombinant FVIII (Safacto ${ }^{\circ}$ ) versus recombinant FVIII (Xyntha ${ }^{\circ}$ ) in patients with severe hemophilia A.

\section{Materials and Methods}

Ethics Committee of the Baqiyatallah University of Medical Sciences (Tehran, Iran) approved the study pro- tocol. The study was performed in agreement with the declaration of Helsinki and good clinical practice. All subjects were informed about the study and a written consent was obtained from the patients at the time of study entry. This study was also registered in the Iranian Registry of Clinical Trials (IRCT) (registration number: IRCT2014101218870N2). This trial was designed as triple-blind and parallel.

The inclusion criteria of the study were (1) patients with severe hemophilia A; (2) without inhibitors against factor VIII; (3) receiving factor VIII for more than 50 days; (4) having blood tests within the normal reference ranges; and (5) having acute or subacute hemarthroses. Exclusion criteria of this study were (1) patients with the history of factor VIII inhibitors; (2) patients with the history of other coagulation disorders except for hemophilia; (3) patients with the history of hepatitis; (4) patients with renal or liver failure; (5) HIV-positive patients; and (6) patients with any infection; allergy or severe adverse effect diagnosed by the physician.

Thirty-three male patients with severe hemophilia A were randomly divided into two groups. In group A (17 patients), patients received Safacto ${ }^{\circ}$ (Saman Daroo 8 Pharmaceutical Company, Tehran, Iran), and in group B (16 patients) patients received Xyntha ${ }^{\circledR}$ (Pfizer Inc, New York, NY, USA) for four consecutive times. The dosage of FVIII was $50 \mathrm{IU} / \mathrm{kg}$ for each injection. The dosage was constant for each patient. Vital signs, adverse effects, every symptom and clinical response after drug administration were monitored. The efficacy and safety of these two recombinant FVIIIs were compared. Plasma level of FVIII activity was evaluated before every injection, 15 minutes after the injection and one month after the start of the trial. The rate of factor VIII activity, pain and joints motion were assessed before and after the treatment as response criteria. Any adverse effect was recorded. Kavakli global response scoring system [6] was used to evaluate pain and joints motion at 1, 3, 8, 12, 16 and 24 hours after drug administration.

Complete blood count and biochemistry profile were assessed before and after the trial. Chromogenic assay and Nijmegen inhibitory assay methods were used to evaluate plasma level of FVIII activity by the Iran Blood Transfusion Organization (IBTO) [2]. Patients stayed in the hospital for three hours and discharged if they were symptom-free. Patients were already informed about potential adverse drug reactions.

Statistical analysis was performed using SPSS software (SPSS Version 16, IBM Corp., New York, NY, USA). Data were analyzed using a t-test for data with normal distribution, and Mann-Whitney U test for data without normal distribution. Independent categorical data were compared using Chi-square and Fishers' exact tests, and dependent categorical data were compared using the McNemar test. P-value of $<0.05$ was considered as statistically significant. Data were expressed as Mean \pm SD.

\section{Results}

Thirty-three male patients with severe hemophilia A were enrolled in this study. No patient was excluded from the 
study. Mean age of the patients were $19.44 \pm 17.00$ and $16.47 \pm 17.0$ in Safacto ${ }^{\circ}$ and Xyntha ${ }^{\circ}$ groups, respectively. Mean body weight of the patients were $52.50 \pm 56.50$ and $43.47 \pm 50.00$ in Safacto $^{\circ}$ and Xyntha ${ }^{\circ}$ groups, respectively. No significant difference was observed between Safacto ${ }^{\circ}$ and Xyntha ${ }^{\circ}$ groups with respect to weight and age of the patients $(\mathrm{P}=0.24, \mathrm{P}=0.44)$. Total drug dosage in Safacto ${ }^{\circ}$ and Xyntha $^{\circ}$ groups were 2603.3 $\pm 2750.0 \mathrm{IU}$ and $2050.0 \pm 2250.0$ IU, respectively (Table1). Plasma level of FVIII clotting activity in Safacto ${ }^{\circ}$ and Xyntha ${ }^{\circ}$ groups were $1.96 \pm 0.5 \mathrm{IU} / \mathrm{dl}$ and $1.63 \pm 0.5 \mathrm{IU} / \mathrm{dl}$ and increased to $88.84 \pm 25.2 \mathrm{IU} / \mathrm{dl}$ and $100.09 \pm 17.8 \mathrm{IU} / \mathrm{dl}$, respectively. This increase was significant in both groups $(\mathrm{P}<0.001)$. There was no significant difference between Safacto ${ }^{\circ}$ and Xyntha ${ }^{\circ}$ groups before and after the trial $(\mathrm{P}>0.31)$ (Table 2).

The mean \pm SD value of total pain score and range of motion improvement were $9.3 \pm 0.9$ and $8.7 \pm 0.1$ with Safacto ${ }^{\circ}$ $(\mathrm{P}=0.17)$; and $9.4 \pm 0.8$ and $8.8 \pm 0.3$ with $\mathrm{Xyntha}^{\circ}(\mathrm{P}=0.35)$, respectively. Joint Range of Motion and Pain scores after injection in each group at different time points are summarized in Tables 3 and 4.

\section{Discussion}

All patients participated in this study because of occurrence of bleeding. In the Safacto ${ }^{\circ}$ group, 16 patients had spontaneous bleeding and one had traumatic bleeding. In the Xyntha ${ }^{\circ}$ group, all patients experienced spontaneous bleeding. Both recombinant FVIII products were used in our study as on-demand treatment. In our study, no adverse effect was observed and the patients well tolerated both drugs.

Local recombinant coagulation factors have been produced by some Iranian pharmaceutical companies. Both Iranian recombinant FVII (Aryoseven ${ }^{\circ}$ ) and FVIII (Safacto ${ }^{\circ}$ ) have been used in the patients with coagulation disorders. In 2015, Eshghi and others compared the safety and efficacy of the Safacto ${ }^{\circ}$ with plasma- derivedFVIII[7].Safacto ${ }^{\circ}$ increasedthelevelofFVIIIserumactivitymorethantheplasma- derivedproduct[8].However,thedifferencewasnotsignificant.BothSafacto ${ }^{\circ}$ andplasma- derived FVIII were safe and efficient in the treatment of hemophilia A [8]. After drug therapy, the plasma level of FVIII activity in Safacto ${ }^{\circ}$ and plasma-derived FVIII groups were $115 \mathrm{IU} / \mathrm{dl}$ and 111 IU/dl, respectively [9].

Toogeh et al. evaluated the safety of the Iranian recombinant activated FVII (Aryoseven ${ }^{\circ}$ ) in patients with bleeding [10]. They stated that careful dosing of Aryoseven ${ }^{\circ}$ is needed to reduce potential side effects of this drug. Only $5.9 \%$ of the patients reported any side effects, though no long-term follow-up was performed by the investigators. In a study by Faranoush and others (2016), the safety and efficacy of Aryoseven ${ }^{\circ}$ and NovoSeven ${ }^{\circ}$ were compared in patients with hereditary FVII deficiency. In their study, clinical efficacy of Aryoseven ${ }^{\circ}$ and NovoSeven ${ }^{\circ}$ were found to be the same using the Kavakli Global Response Scoring System.Inthementionedstudy,FVIIlevelbeforeandafterthetreatmentinAryoseven ${ }^{\circ}$ and NovoSeven ${ }^{\circ}$ groups were $100 \mathrm{IU} / \mathrm{dl}$ and $88 \mathrm{IU} / \mathrm{dl} ; 800 \mathrm{IU} / \mathrm{dl}$ and $800 \mathrm{IU} / \mathrm{dl}$, respectively. From 31 patients in the Aryoseven group, only three experienced nausea, rash and headache. In the NovoSeven ${ }^{\circ}$ group, only one patient had a headache [11].
Comparison of plasma-derived and recombinant FVIII pharmacokinetics has been performed by Morfini et al. [12]. Higher in vivo recovery was reported for recombinant FVIII while elimination decay curves of both products were the same. Alpha constant and half-life of recombinant FVIII was smaller and longer compared to plasma-derived FVIII, respectively [12].

In the guideline of the committee for medicinal products for human use (2011) about the use of recombinant FVIII in hemophilia patients, the most frequent complication in patients was the production of inhibitory antibodies against the drug [13]. In 2007, Chalmers and others evaluated 384 patients for the effect of first exposure on the production of inhibitor in children. In their study, neonatal exposure to FVIII was not associated with a higher incidence of inhibitors [14]. In a retrospective cohort study, Gouw et al. (2007) showed that incidence of inhibitors in patients with severe hemophilia A was not dependent on the type of product. They did not find a significant difference between serum-derived FVIII and recombinant one in the incidence of inhibitors [15].

Survey of Inhibitors in Plasma-Product Exposed Toddlers (SIPPET) was performed by Peyvandi et al.A total of 303 patients were screened for inhibitors. Seventy-six patients developed inhibitors and fifty of them had high-titer inhibitors (more than $5 \mathrm{BU}$ ). The authors reported that patients treated with plasma-derived FVIII had a lower incidence of inhibitors in comparison to the recombinant group [16].

Lee in 2002 used three recombinant FVIII (Kogenate, Recombinate, and rVIII-SQ) for the management of hemophilia A. All three products had good efficacy and safety after a single injection with a dosage between 20 and 30 IU $/ \mathrm{kg}$. The half-life of the three products was reported to be 14-15 hours [17]. The dosage of recombinant FVIII in our study was $40-50 \mathrm{IU} / \mathrm{kg}$; we did not measure half-life and it was a limitation of our study. In 2003, Lusher and others evaluated safety and efficacy of B-domain-deleted recombinant factor VIII (ReFacto ${ }^{\circ}$ in 218 hemophilic patients. The drug was rated with excellent efficacy [18]. Ragni in 2017 assessed the safety and efficacy of recombinant FVIII as prophylaxis, when administered once weekly or three times weekly. In their study, $40 \mathrm{IU} / \mathrm{Kg}$ of recombinant FVIII was administered to the patients. The main outcome in the patients was low spontaneous or traumatic bleeding in both prophylaxis protocols. There was no difference in coagulation levels, the range of motion and quality of life in all the patients [19].

Saxena and colleagues in 2016 evaluated the efficacy and safety of Kovaltryo in hemophilia patients. Sixty-two patients received 20-50 IU $/ \mathrm{kg}$ of recombinant FVIII twice or three times weekly. Both protocols were effective to maintain hemostasis during surgery and stopped bleeding in the patients [20].

Nolan and others (2016) evaluated the safety and efficacy of recombinant factor VIII Fc fusion protein in patients with hemophilia [12]. Long-term use of this recombinant FVIII maintained the low average bleeding rate and increased intervals of prophylactic injections [21]. Efficacy of pegylated full-length recombinant FVIII for the prophylactic and on-demand management of patients with severe hemophilia A was assessed by Konkle and 
creased intervals of prophylactic injections [21].

Efficacy of pegylated full-length recombinant FVIII for the prophylactic and on-demand management of patients with severe hemophilia A was assessed by Konkle and others (2015) [22]. Annualized bleeding rate in on-demand use was higher than the prophylaxis regimen. The authors reported effectiveness and safety of the recombinant FVIII with twice-weekly infusions [22].

Recombinant factor VIII Fc fusion protein was used in children with severe hemophilia [15]. The drug was used as prophylaxis for 71 patients with a dose of $\leq 80 \mathrm{IU} / \mathrm{Kg}$. Patients well tolerated two weekly infusions with low bleeding rate [23]. It is worth mentioning that small population size with low bleeds incidence was another limitation of our study.

\section{Conclusions}

Overall, both recombinant factors administered on-demand in this study had no significant side effects in patients with severe hemophilia. Our study did not show a significant difference in efficacy and safety between Safacto $^{\circ}$ and Xyntha ${ }^{\circ}$. A significant increase in serum level of
FVIII activity without noticeable side effect was observed during the study.

Improvement in joint range of motion, a decrease of pain and control of bleeding were predominant findings in both Safacto ${ }^{\circ}$ and Xyntha ${ }^{\circ}$ groups. No allergic reaction was observed in patients with hemophilia A after Safacto ${ }^{\circ}$ administration. The results of this study showed that Safacto ${ }^{\circ}$ has favorable safety and efficacy. Future studies exploring the immunogenicity of Safacto ${ }^{\oplus}$ are warranted.

\section{Acknowledgments}

The authors are grateful to the Saman Darou 8 Pharmaceutical Company (Mashhad, Iran) that provided both drugs (Safacto ${ }^{\circ}$ and Xyntha ${ }^{\circ}$ ) for this study. We are also thankful to the Iranian Blood Transfusion Organization and Clinical Research and Development Unit of the Baqiyatallah Hospital (Tehran, Iran) for their help in conducting the present study.

\section{Conflict of interest}

The authors declare that there is no conflict of interests.

Table 1 Age, body weight and total drug dosage in both groups

\begin{tabular}{ccccccccccc}
\hline Parameters & \multicolumn{3}{c}{ Safacto ${ }^{\circledR}$} \\
\cline { 2 - 8 } & Mean & Median & IQR & SD & Mean & Median & IQR & SD & Value \\
Age & 19.44 & 10.22 & 18 & 17.00 & 16.47 & 6.78 & 12 & 17.00 & 0.187 \\
Weight & 52.50 & 23.97 & 34 & 56.50 & 43.47 & 16.76 & 34 & 50.00 & 0.446 \\
TDD & 2603.33 & 1238.73 & 2000 & 2750.00 & 2050.00 & 808.88 & 1200 & 2250.00 & 0.247
\end{tabular}

IQR: Interquartile range TDD: Total Drug Dosage

Table 2 Plasma FVIII level in two groups

\begin{tabular}{|c|c|c|c|c|c|c|c|c|c|}
\hline \multirow[t]{3}{*}{ Group } & \multicolumn{3}{|c|}{ Baseline level of FVIII } & \multirow{2}{*}{\multicolumn{3}{|c|}{$\begin{array}{c}\text { Level of FVIII, } 15 \text { minutes } \\
\text { PI }\end{array}$}} & \multirow{3}{*}{$\begin{array}{c}\text { P- } \\
\text { Value }\end{array}$} & \multirow{3}{*}{$\begin{array}{c}\text { Mean } \\
\text { Differenc } \\
\text { e }\end{array}$} & \multirow{3}{*}{$\begin{array}{c}\text { Between } \\
\text { Group P } \\
\text { Value }\end{array}$} \\
\hline & & & & & & & & & \\
\hline & Mean & Median & IQR & Mean & Median & IQR & & & \\
\hline Safacto & 1.96 & 2.00 & 0.5 & 88.84 & 98.00 & 25.2 & $<0.001$ & 86.88 & 0.316 \\
\hline \multicolumn{10}{|l|}{ (B) } \\
\hline Xyntha & 1.63 & 1.00 & 0.5 & 100.09 & 116.00 & 17.8 & $<0.001$ & 98.46 & \\
\hline (B) & & & & & & & & & \\
\hline
\end{tabular}

IQR: Interquartile range 
Table 3 Joint range of motion after treatment in two groups

\begin{tabular}{|c|c|c|c|c|c|}
\hline \multirow[t]{2}{*}{ Time } & \multicolumn{2}{|c|}{ Safacto® } & \multicolumn{2}{|c|}{ Xyntha® } & \multirow[t]{2}{*}{ P-Value } \\
\hline & Mean & $\mathrm{SD}$ & Mean & SD & \\
\hline Time of & 1.2 & 0.4 & 1.1 & 0.3 & 0.096 \\
\hline \multicolumn{6}{|l|}{ Injection } \\
\hline 3 hrs. PI & 1.3 & 0.5 & 1.2 & 0.4 & 0.052 \\
\hline 8 hrs. PI & 1.5 & 0.6 & 1.5 & 0.5 & 0.051 \\
\hline 12 hrs. PI & 1.4 & 0.9 & 1.5 & 0.8 & 0.909 \\
\hline 16 hrs. PI & 1.5 & 0.9 & 1.4 & 0.9 & 0.257 \\
\hline 24 hrs. PI & 1.6 & 0.8 & 1.5 & 0.9 & 0.086 \\
\hline Total Score & 1.41 & 0.51 & 1.39 & 0.45 & 0.351 \\
\hline
\end{tabular}

PI: Post Injection

Table 4 Pain after treatment in two groups

\begin{tabular}{|c|c|c|c|c|c|}
\hline \multirow[t]{2}{*}{ Time } & \multicolumn{2}{|c|}{ Safacto® } & \multicolumn{2}{|c|}{ Xyntha® } & \multirow[t]{2}{*}{ P-Value } \\
\hline & Mean & $\mathrm{SD}$ & Mean & SD & \\
\hline Time of & 1.3 & 0.5 & 1.3 & 0.4 & 0.096 \\
\hline \multicolumn{6}{|l|}{ Injection } \\
\hline 3 hrs. PI & 1.4 & 0.5 & 1.4 & 0.5 & 0.051 \\
\hline 8 hrs. PI & 1.7 & 0.5 & 1.5 & 0.5 & 0.051 \\
\hline 12 hrs. PI & 1.6 & 0.8 & 1.7 & 0.7 & 0.909 \\
\hline 16 hrs. PI & 1.6 & 0.8 & 1.4 & 0.9 & 0.257 \\
\hline 24 hrs. PI & 1.5 & 0.9 & 1.3 & 0.9 & 0.086 \\
\hline Total Score & 1.53 & 0.49 & 1.44 & 0.48 & 0.171 \\
\hline
\end{tabular}

PI: Post Injection 


\section{References}

1. Mannucci PM, Tuddenham EG. The hemophilias--from royal genes to gene therapy. $\mathrm{N}$ Engl J Med. 2001; 344(23): 1773-9.

2. White GC 2nd, et al. Definitions in hemophilia. Recommendation of the scientific subcommittee on factor VIII and factor IX of the scientific and standardization committee of the International Society on Thrombosis and Haemostasis. Thromb Haemost. 2001; 85(3): 560.

3. Cheraghali A. Cost effectiveness of Iran national plasma contract fractionation program. DARU Journal of Pharmaceutical Sciences, 2012; 20(1): 63.

4. Faranoush M. Patients Perspective in Plasma Products (Focus on Hemophilia). Iranian Journal of Blood and Cancer. 2011; 3(3): 171-5.

5. Cheraghali AM, Aboofazeli R. Economical impact of plasma fractionation project in Iran on affordability of plasma-derived medicines. Transfusion Medicine. 2009; 19(6): 363-8.

6. Cheraghali AM, Eshghi P. Cost Assessment of Implementation of Immune Tolerance Induction in Iran. Value in Health Regional Issues. 2012; 1(1): 54-8.

7. Eshghi P, Abolghasemi H, Malek F, Naderi M, Panahi Y, Habibpanah B, et al. A prospective Crossover Triple-blind Controlled Trial on the Safety and Efficacy of Iranian Recombinant FVIII (Safacto) versus Plasma Derived FVIII A pilot study. Iranian Journal of Blood and Cancer. 2015; 7(4): 171-4.

8. Kavakli K, Makris M, Zulfikar B, Erhardtsen E, Abrams ZS, Kenet G; NovoSeven trial (F7HAEM-1510) investigators. Home treatment of haemarthroses using a single dose regimen of recombinant activated factor VII in patients with haemophilia and inhibitors. A multi-centre, randomised, double-blind, cross-over trial. Thromb Haemost. 2006; 95(4): 600-5.

9. Verbruggen, B, van Heerde W, Laros-van Gorkom B. Improvements in Factor VIII Inhibitor Detection: From Bethesda to Nijmegen. Seminars in Thrombosis and Hemostasis. 2010; 35(8): 752-9.

10. Toogeh G, Abolghasemi H, Eshghi P, Managhchi M, Shaverdi-Niasari M, Karimi K, et al. Evaluation of Aryoseven Safety (Recombinant Activated Factor VII) in Patients with Bleeding Disorders (An Observational Post-Marketing Surveillance Study). Iran J Pathol. 2016; 11(3): 204-9.

11. Faranoush M, Abolghasemi H, Mahboudi F, Toogeh G, Karimi M, Eshghi P, et al. A Comparison of Efficacy Between Recombinant Activated Factor VII (Aryoseven) and Novoseven in Patients With Hereditary FVIII Deficiency With Inhibitor. Clin Appl Thromb Hemost. 2016; 22(2): 184-90.

12. Morfini M, Marchesini E, Paladino E, Santoro C, Zanon E, Iorio A, et al. Pharmacokinetics of plasma-derived vs. recombinant FVIII concentrates: a comparative study. Haemophilia. 2015; 21(2): 204-9.

13. European Medicines Agency. Guideline on the clinical investigation of recombinant and human plasma-derived factor VIII products. 2011 [cited $201725 \mathrm{March}$ ].

14. Chalmers EA, Brown SA, Keeling D, Liesner R, Richards M, Stirling D, et al. Early factor VIII exposure and sub- sequent inhibitor development in children with severe haemophilia A. Haemophilia. 2007; 13(2): 149-55.

15. Gouw SC, van der Bom JG, Auerswald G, Ettinghausen CE, Tedgård U, van den Berg HM. Recombinant versus plasma-derived factor VIII products and the development of inhibitors in previously untreated patients with severe hemophilia A: the CANAL cohort study. Blood. 2007; 109(11): 4693-7.

16. F. Peyvandi, P.M. Mannucci, I. Garagiola, A. El冈Beshlawy, M. Elalfy, V. Ramanan, et al. A Randomized Trial of Factor VIII and Neutralizing Antibodies in Hemophilia A. New England Journal of Medicine. 2016; 374(21): 2054-64.

17. Lee C. The Use of Recombinant Factor VIII Products in Previously Treated Patients with Hemophilia A: Pharmacokinetics, Efficacy, Safety, and Inhibitor Development. Semin Thromb Hemost. 2002; 28(3): 241-6.

18. Lusher JM, Lee CA, Kessler CM, Bedrosian CL; ReFacto Phase 3 Study Group. The safety and efficacy of B-domain deleted recombinant factor VIII concentrate in patients with severe haemophilia A. Haemophilia. 2003; 9(1): 38-49.

19. Ragni MV, Yabes JG, Fogarty PF, Josephson NC, Kessler $\mathrm{CM}$, Neff AT, et al. Pilot randomized, non-inferiority, cross-over trial of once-weekly vs. three times-weekly recombinant factor VIII prophylaxis in adults with severe haemophilia A. Haemophilia. 2017; 23(1): e43-e6.

20. Saxena K, Lalezari S, Oldenburg J, Tseneklidou-Stoeter D, Beckmann H, Yoon M, et al. Efficacy and safety of BAY 81-8973, a full-length recombinant factor VIII: results from the LEOPOLD I trial. Haemophilia. 2016; 22(5): 706-12.

21. Nolan B, Mahlangu J, Perry D, Young G, Liesner R, Konkle B, et al. Long-term safety and efficacy of recombinant factor VIII Fc fusion protein (rFVIIIFc) in subjects with haemophilia A. Haemophilia. 2016; 22(1): 72-80.

22. Konkle BA, Stasyshyn O, Chowdary P, Bevan DH, Mant T, Shima M, et al. Pegylated, full-length, recombinant factor VIII for prophylactic and on-demand treatment of severe hemophilia A. Blood. 2015;126(9): 1078-85.

23. Young G, Mahlangu J, Kulkarni R, Nolan B, Liesner R, Pasi J, et al., Recombinant factor VIII Fc fusion protein for the prevention and treatment of bleeding in children with severe hemophilia A. J Thromb Haemost. 2015; 13(6): 967-77. 